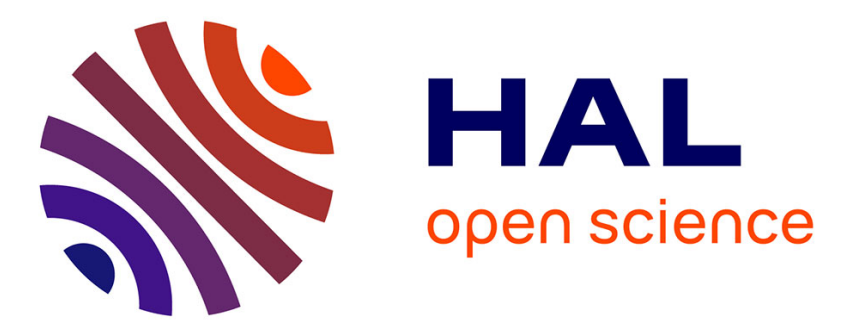

\title{
An in-situ x-ray diffraction and infrared spectroscopic study of the dehydration of AlPO4-54
}

Marco Fabbiani, Michelangelo Polisi, Bernard Fraisse, Rossella Arletti, Mario Santoro, Frederico Alabarse, Julien Haines

\section{- To cite this version:}

Marco Fabbiani, Michelangelo Polisi, Bernard Fraisse, Rossella Arletti, Mario Santoro, et al.. An in-situ x-ray diffraction and infrared spectroscopic study of the dehydration of AlPO4-54. Solid State Sciences, 2020, 108, pp.106378. 10.1016/j.solidstatesciences.2020.106378 . hal-02943271

\section{HAL Id: hal-02943271 \\ https://hal.science/hal-02943271}

Submitted on 18 Sep 2020

HAL is a multi-disciplinary open access archive for the deposit and dissemination of scientific research documents, whether they are published or not. The documents may come from teaching and research institutions in France or abroad, or from public or private research centers.
L'archive ouverte pluridisciplinaire HAL, est destinée au dépôt et à la diffusion de documents scientifiques de niveau recherche, publiés ou non, émanant des établissements d'enseignement et de recherche français ou étrangers, des laboratoires publics ou privés. 


\title{
An in-situ x-ray diffraction and infrared spectroscopic study of the dehydration of
}

\author{
$\mathrm{AlPO}_{4}-54$ \\ Marco Fabbiani $^{\mathrm{a}, \mathrm{b}}$, Michelangelo Polisi ${ }^{\mathrm{a}, \mathrm{c}}$, Bernard Fraisse ${ }^{\mathrm{a}}$, Rossella Arlettic, Mario Santoro ${ }^{\mathrm{d}}$, \\ Frederico Alabarse ${ }^{\mathrm{e}}$, Julien Haines*a. \\ ${ }^{a} I C G M$, CNRS, Université de Montpellier, ENSCM, Montpellier, France. \\ ${ }^{b}$ Dipartimento di chimica, Università di Torino, Italy. \\ ${ }^{c}$ Dipartimento di Scienze Chimiche e Gelogiche, Università degli Studi di Modena e Reggio Emilia, \\ Modena, Italy. \\ ${ }^{d}$ Istituto Nazionale di Ottica CNR and European Laboratory for Non Linear Spectroscopy, Sesto \\ Fiorentino, Italy \\ ${ }^{e}$ Elettra Sincrotrone Trieste, Trieste, Italy.
}

*Corresponding Author: Julien Haines: Julien.Haines@umontpellier.fr

\section{ABSTRACT}

The dehydration of the large pore aluminophosphate $\mathrm{AlPO}_{4}-54 \cdot x \mathrm{H}_{2} \mathrm{O}$ was studied in situ as a function of vacuum pressure at room temperature by infrared spectroscopy and x-ray diffraction. On polycrystalline samples, under primary vacuum, the adsorbed water is removed very rapidly. The structural water in the $\mathrm{AlO}_{6}$ octahedra is then removed slowly with the quantity of the fully dehydrated form gradually increasing from 43 to $65 \%$ of the total material. This results in a two-phase mixture of fully dehydrated and a distinct partially dehydrated $\mathrm{AlPO}_{4}-54 \bullet 1 / 2 \mathrm{H}_{2} \mathrm{O}$ phase containing structural water. These phases have almost identical $a$ cell parameters and very close $c$ parameters. Secondary vacuum increases the amount of fully 
dehydrated material to more than $76 \%$. Prolonged heating under vacuum increases the amount of fully dehydrated material to $90 \%$. On single crystal samples, removal of adsorbed water is slower and results in a reduction in crystal quality, however prolonged exposure to primary vacuum yielded fully dehydrated material without the need for heating. The monoclinic structure of anhydrous AlPO4-54, space group $\mathrm{Cm}$, with a doubled unit cell was confirmed using single crystal synchrotron $\mathrm{x}$-ray diffraction data.
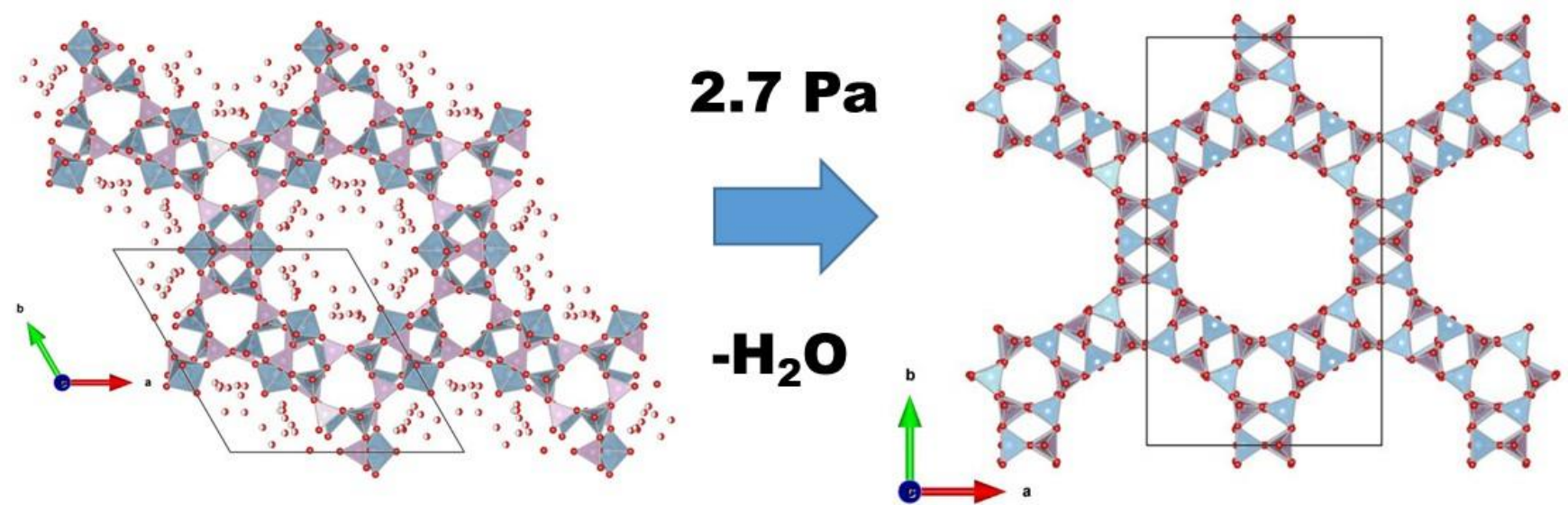

\section{HIGHLIGHTS:}

- Structural water in the Al octahedra is gradually removed as a function of vacuum pressure and time

- In powder samples, an intermediate, partially dehydrated $\mathrm{AlPO}_{4}-54 \cdot 1 / 2 \mathrm{H}_{2} \mathrm{O}$ phase containing structural water is observed

- The monoclinic $\mathrm{Cm}$ structure of anhydrous AlPO4-54 was confirmed by single crystal synchrotron x-ray diffraction.

\section{KEYWORDS:}

Aluminophosphate, dehydration, x-ray diffraction, infrared spectroscopy

\section{Introduction}

$\mathrm{AlPO}_{4}-54 \cdot x \mathrm{H}_{2} \mathrm{O}$, also known as VPI-5, with the VFI structure type[1] is the aluminophosphate with the largest pores[2]. This material has a one dimensional pore system with $12.7 \AA$ pores lying along the $\mathbf{c}$ 
direction. The hexagonal structure of this material, space group $P 6_{3}$ with $a=18.9752 \AA$ and $c=8.1044 \AA$ has been refined using powder [3] and single crystal x-ray diffraction [4-6]. It consists of a framework of alternating Al-centered polyhedra and $\mathrm{P}$-centered tetrahedra. The $\mathrm{Al}$ atoms are in different environments; one third are in octahedral coordination due to the presence of two water molecules in the coordination sphere, the remaining two thirds of the $\mathrm{Al}$ atoms are in tetrahedral coordination. In addition to the structural water, the pores also contain confined adsorbed water, which presents some degree of order[3]. This is in fact a model system for the confinement of water at the nanoscale[4].

AlPO4-54. $x \mathrm{H}_{2} \mathrm{O}$ can be dehydrated with great care conserving the framework structure and removing the structural and adsorbed water[7-12]. This results in the Al atoms all being tetrahedrally coordinated. The dehydration process involves the use of vacuum and/or heating and if it is not optimized, transformation to a smaller-pore aluminophosphate $\mathrm{AlPO}_{4}-8$ is observed[12-14]. The dehydrated form of this material is of interest as the removal of water can allow for the insertion of other guests.

Using neutron powder diffraction, the structure of dehydrated VFI was first refined using a $P 6_{3} / \mathrm{mcm}^{2}$ model with $a=18.549 \AA$ and $c=8.404 \AA$ as the $\mathrm{Al}$ and $\mathrm{P}$ atoms could not be distinguished[7]. Subsequent x-ray powder diffraction studies indicated that the symmetry was in fact lower with a $P 6_{3} \mathrm{~cm}$ space group due to alternating $\mathrm{AlO}_{4}$ and $\mathrm{PO}_{4}$ tetrahedra in the structure[8]. NMR studies confirm that all the $\mathrm{Al}$ atoms are in tetrahedral coordination; however, ${ }^{31} \mathrm{P}$ NMR spectra are not in agreement with such high hexagonal symmetry[9].

In addition, unit cell parameters differ depending on the vacuum pressure, temperature and duration of the treatment, for example after $8 \mathrm{~h}$ at $1.3 \mathrm{mPa}$ the unit cell parameters were found to be $a=18.524 \AA$ and $c=8.332 \AA[10]$ as compared to $a=18.544 \AA$ and $c=8.3847 \AA$ after $48 \mathrm{~h}$ at $0.1 \mathrm{~Pa}[11]$, with no further evolution under high vacuum nor with heating. Very long dehydration with increasing vacuum and temperature over the period of one week produced a hexagonal material with $a=18.5457 \AA$ and $c=8.3992 \AA$ [15].

It was later shown that the structure and cell parameters also depend on the age of the sample and its detailed history[9]. In the latter study, dehydrated VFI was found to adopt two monoclinic $C m$ structures 
with simple and doubled $c$ lattice parameters. No deviation from a hexagonal unit cell metric was ob-

served. The ${ }^{31} \mathrm{P}$ NMR spectra of both materials are the same and are not consistent with these monoclinic crystal structures. It was proposed that these monoclinic structures are commensurate or incommensurate modulated structures.

In the present study, in order to determine the conditions required for dehydration of VFI without the need for heating for optimized filling with other guest species, an in situ study under vacuum by infrared spectroscopy, powder and synchrotron single crystal x-ray diffraction was performed.

\section{Experimental Section}

\subsection{Synthesis of $\mathrm{AlPO}_{4}-54 . x \mathrm{H}_{2} \mathrm{O}$}

Polycrystalline samples and large single crystals, with linear dimensions on the order of $30 \times 1 \times 1 \mu \mathrm{m}^{3}$ and $200 \times 25 \times 25 \mu \mathrm{m}^{3}$ (needle-like), respectively, were synthesized by an optimized sol-gel procedure followed by hydrothermal treatment. The starting materials for the synthesis of the polycrystalline material were nanometric alumina and phosphoric acid. An alternative method using polyphosphoric acid was used for the synthesis of the large single crystals[16]. The details of the synthesis for both samples can be found elsewhere $[4,15,17]$. The polycrystalline material was ground prior to the in situ studies under vacuum.

\subsection{In situ infrared spectroscopy under vacuum}

In situ Fourier Transform Infrared spectroscopy (FTIR) was carried out on a self-supported pellet of VFI using a traditional fused quartz cell with $\mathrm{CaF}_{2}$ windows, connected to a vacuum line. The IR spectra were collected on a Bruker IFS66 equipped with a Globar source, KBr beamsplitter and La-DTGS (deuterated triglycine sulfate) detector, by averaging 64 scans at $4 \mathrm{~cm}^{-1}$ resolution to attain a good S/N ratio. The sample was evacuated with two different pumping systems: one formed by an oil free primary rotary vane pump and a secondary vacuum system formed by a turbomolecular pump coupled with the primary pump. 
The isotopic exchanges were carried out by contacting a previously evacuated sample with $\mathrm{D}_{2} \mathrm{O}$ vapors (ca. 30 mbar at room temperature) and removing the excess by further evacuating the system, thus completing a cycle. A total of 5 cycles are performed to ensure the complete exchange of all the dissociable protons.

\subsection{In situ single-crystal $x$-ray diffraction under vacuum}

In situ single crystal synchrotron X-ray diffraction (XRD) measurements under vacuum were performed using a vacuum chamber with Mylar and Kapton windows custom designed for a diamond anvil cell (DAC)[18] on the high pressure diffraction beamline Xpress at the Elettra Sinchrotrone Trieste Facility. The Almax-EasyLab Plate DAC used had $500 \mu \mathrm{m}$ diamond culets size with a Boehler-Almax design and an $85^{\circ} 4 \theta$ X-ray opening. A $200 \times 25 \times 25 \mu \mathrm{m}^{3}$ single crystal was placed in the $300 \mu \mathrm{m}$ diameter hole of a $60 \mu \mathrm{m}$ thick stainless steel gasket in the DAC.

XRD data were obtained with large 2D MAR345 image plate detector using a $150 \mu \mathrm{m}$ pixel size. The incident wavelength was $0.4957 \AA$ and an $80 \mu$ m diameter pinhole was used to provide the small incident beam. $\mathrm{CeO}_{2}$ powder was used to calibrate the diffractometer with the Fit2d[19] software calibration tool, giving the distance between the sample and the detector of $350.162 \mathrm{~mm}$. An $\alpha$-quartz single crystal was used to determine the instrumental parameters for the diffractometer. Phi-scans from -23 to $+23^{\circ}$ in $1^{\circ}$ steps were performed. The maximum angle was limited by possible collisions. The exposure time was 2 s per frame. Details concerning in situ synchrotron XRD measurements on single crystals by using a DAC at Xpress can be found elsewhere[20].

The data were indexed, reduced and corrected for absorption using CrysalisPro (Rigaku). Structure refinements were performed using SHELXL97[21]. The known twinning of the crystals on the (100) face was included in the refinement. Soft constraints were placed on the Al-O and P-O distances and like atoms were constrained to have identical atomic displacement parameters. Crystal structures were plotted using the program VESTA[22]. 


\subsection{In situ x-ray powder diffraction under vacuum}

X-ray powder diffraction measurements under vacuum were performed in an Anton Paar HTK16 oven

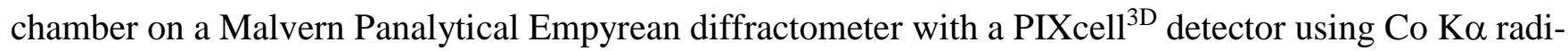
ation $\left(\lambda=1.7903 \AA\right.$ ). The polycrystalline $\mathrm{AlPO}_{4}-54 \bullet x \mathrm{H}_{2} \mathrm{O}$ was dispersed in ethanol and evenly spread out over the platinum strip of the oven chamber. Diffraction data were obtained over an angular range from $4^{\circ}$ to $100^{\circ}$ in $2 \theta$ with a step size of $0.013^{\circ}$. The overall acquisition time was $3 \mathrm{~h}$. The program Fullprof [23] was used to perform Le Bail fits in order to determine the unit cell parameters.

\section{Results and discussion}

\subsection{In situ infrared spectroscopy under vacuum}

The infrared spectrum of $\mathrm{AlPO}_{4}-54 \cdot x \mathrm{H}_{2} \mathrm{O}$ was measured as a function of time and vacuum pressure, Fig.1. As the $\mathrm{OH}$ stretching region contains band from water and also hydroxyl defects in the framework, attention was primarily focused on the bending vibration of $\mathrm{H}_{2} \mathrm{O}$ at $1632 \mathrm{~cm}^{-1}$. This band loses $88.3 \%$ of its intensity after $2 \mathrm{~h}$ in primary vacuum $(5 \mathrm{~Pa})$ and $94.2 \%$ of its intensity after $2 \mathrm{~h}$ in secondary vacuum $(0.05 \mathrm{~Pa})$. These results provide quantitative information on the residual water content of partially dehydrated $\mathrm{AlPO}_{4}-54 . x \mathrm{H}_{2} \mathrm{O}$. Previous studies indicate that $\mathrm{AlPO}_{4}-54 \cdot x \mathrm{H}_{2} \mathrm{O}$ contains close to 24 wt $\% \mathrm{H}_{2} \mathrm{O}[9]$ corresponding to an $x$ value of about 2.14. The IR intensities would be consistent with a value of $x$ of 0.25 under primary vacuum and $x=0.12$ under secondary vacuum. In the framework of $\mathrm{AlPO}_{4}-54 \bullet x \mathrm{H}_{2} \mathrm{O}, 1 / 3$ of the $\mathrm{Al}$ atoms are in octahedral coordination with 2 water molecules in the coordination sphere. If only this structural water remains in $\mathrm{AlPO}_{4}-54 \bullet x \mathrm{H}_{2} \mathrm{O}$, then $x$ would be equal to 0.67 . The present IR results indicate that all the adsorbed water in the pores is removed along with $63 \%$ of the structural water under primary vacuum and $82 \%$ of the structural water under secondary vacuum after $2 \mathrm{~h}$.

\subsection{In situ single-crystal $x$-ray diffraction under vacuum}

In previous work as discussed in the introduction, various hexagonal and monoclinic structures have been proposed for anhydrous $\mathrm{AlPO}_{4}-54$ based on powder $\mathrm{x}$-ray diffraction[7-9]. In the present work, a high quality single crystal of $\mathrm{AlPO}_{4}-54$ was studied by synchrotron single crystal x-ray diffraction. The 
agreement factors for the measured intensities $R_{\sigma}$ and equivalent reflections $R_{\text {int }}$ were 7.2 and $3.2 \%$, respectively. Refinement was performed using the structural model of $\mathrm{AlPO}_{4}-54 \cdot x \mathrm{H}_{2} \mathrm{O}$ obtained from single crystals from the same synthesis. The final $R_{1}$ agreement factor from the refinement was $3.0 \%$ and the structure was in very good agreement with previous work[4] (unit cell parameters are given in Table 1 and full structural data in the CIF file in supporting information).

After 15 minutes under a primary vacuum pressure of $4 \mathrm{~Pa}$, a notable decrease in crystal quality was observed with $R_{\sigma}$ and $R_{\text {int }}$ values of $29 \%$ and $15 \%$, respectively. A slight decrease in the $a$ lattice parameter was observed, Table 1, but the $c / a$ cell parameter ratio remained typical of $\mathrm{AlPO}_{4}-54 \cdot x \mathrm{H}_{2} \mathrm{O}$. The crystal structure could not be refined reliably.

After $16 \mathrm{~h}$ and a vacuum pressure of $2.7 \mathrm{~Pa}$, an improvement in the $R_{\sigma}$ and $R_{\text {int }}$ for the primitive hexagonal cell was observed with values of $17.7 \%$ and $9.5 \%$, respectively. Inspection of reciprocal lattice reconstructions clearly indicated a doubling of the unit cell along the $\mathbf{c}$ direction, Fig. 2. This cell doubling was already observed on powder samples leading to a monoclinic structure with a space group $\mathrm{Cm}$ [9], which results in a reduction in strain around the $\mathrm{Al}$ site, which was octahedral in the hydrated form. The observed systematic absences are in agreement with a $C$-centered lattice and a mirror plane rather than a $c$-glide plane. Using this structural model[9], a final $R_{1}$ agreement factor of $7.0 \%$ was obtained and the refined structure with fully tetrahedral $\mathrm{Al}$ and no water molecules, Figure 3, is in very good agreement with previous work on samples dehydrated at high temperature[9] and indicate that the full dehydration of single crystals can be performed under vacuum without heating. Vacuum has been previously shown to be a powerful method for dehydration even without heating in the case of the mineral kernite, for example[24]. Cell parameters are given in Table 1. Full details of the refinement and structure can be found in the CIF file in supporting information. The maximum residual electron density on the Fourier difference map of $0.245 \mathrm{e} / \AA^{3}$ is an indication that the pores are empty. No peaks in residual electron density are observed in the region where the structural water was present in the hydrated form.

\subsection{In situ $\mathrm{x}$-ray powder diffraction under vacuum}


The initial powder sample had cell parameters typical of $\mathrm{AlPO}_{4}-54 \bullet x \mathrm{H}_{2} \mathrm{O}$, Table 1 . Several changes in the diffraction pattern are observed under vacuum, Fig. 4. The lower angle diffraction peaks increase in intensity due to the removal of $\mathrm{H}_{2} \mathrm{O}$ molecules which scatter in antiphase, thereby reducing the structure factor for these reflections. The decrease in the $a$ lattice parameter and the increase in $c$ result in significant shifts in the positions of reflections. An additional reflection is observed at a slightly higher angle than the 004 reflection of anhydrous $\mathrm{AlPO}_{4}$. This additional reflection is initially more intense than that of the anhydrous form for a vacuum of $8.9 \mathrm{~Pa}$ and then decreases in intensity as a function of time (Fig. 5) and of vacuum pressure (Fig. 6) indicating that it could correspond to the 004 reflection from an $\mathrm{AlPO}_{4}-54$ phase with some residual $\mathrm{H}_{2} \mathrm{O}$. Similarly, two peaks are also observed for other weaker $h k l(l \neq 0)$ reflections. The changes in relative intensities of these pairs of reflections would be consistent with the corresponding changes in absorbance of the $\mathrm{H}_{2} \mathrm{O}$ bending mode in the infrared data. The relative intensity of the additional " 004 " reflection decreases from $57 \%$ at $8.9 \mathrm{~Pa}$ to $24 \%$ at $0.011 \mathrm{~Pa}$, with the 004 reflection from the anhydrous phase becoming predominant. Upon close inspection of data from a sample, which had been treated for a week under vacuum and at temperatures of $200^{\circ} \mathrm{C}$, a weak residue of this peak was found with a relative intensity of $10 \%$ next to the strong 004 reflection of the anhydrous form. The ability to investigate this two-phase mixture as a function of vacuum pressure has enabled the cell parameters of both forms to be determined, when they are present as the majority phase, Table 1 . The principle difference is $0.1 \AA$ in the $c$ cell parameter. The anhydrous phase always has a typical $c / a$ cell parameter ratio of close to 0.453 in agreement with previous studies of the anhydrous form and the present single crystal data, whereas the corresponding value for the new form is close to 0.450 . The quantity of this form appears to be more correlated to vacuum pressure than time. Based on the infrared spectroscopy results, an estimation of the $\mathrm{H}_{2} \mathrm{O}$ content of this partially hydrated form can be made as the origin of the sample was the same for the IR and XRD studies. The $x$ values from IR spectroscopy were found to be 0.25 and 0.12 for primary and secondary vacuum, respectively. If we consider the two-phase mixture from XRD containing $43 \%$ anhydrous material under primary vacuum after about $2 \mathrm{~h}$ and $76 \%$ anhydrous material after $2 \mathrm{~h}$ of secondary vacuum, the $x$ values of the additional partially hydrated form would be 0.43 and 0.48 for 
primary and secondary vacuum respectively. These values are less than $x=0.67$, which would correspond to a form containing the structural $\mathrm{H}_{2} \mathrm{O}$ coordinated to $1 / 3$ of $\mathrm{Al}$ in octahedral coordination, but with no adsorbed $\mathrm{H}_{2} \mathrm{O}$ in the pores. This would imply that only about $23 \%$ of the $\mathrm{Al}$ atoms are in octahedral coordination. Based on ${ }^{2} \mathrm{H}$ NMR results[25], a similar partially dehydrated form with only framework water in the Al centered octahedra can also be prepared at $373 \mathrm{~K}$. A second possibility is that some Al atoms are in five-fold coordination with only one $\mathrm{H}_{2} \mathrm{O}$ molecule in the coordination sphere. ${ }^{27} \mathrm{Al} \mathrm{NMR}$ provides evidence for this type of configuration in partially hydrated samples[11, 26]. Based on this hypothesis, the IR results would be consistent with an approximately equal proportion of 5-fold and 6-fold coordinated $\mathrm{Al}$ each representing $1 / 6$ of the total $\mathrm{Al}$ atoms.

\section{Conclusion}

The present infrared and x-ray diffraction results on powder samples are consistent with the dehydration of $\mathrm{AlPO}_{4}-54 \cdot x \mathrm{H}_{2} \mathrm{O}$ occurring via a distinct partially dehydrated intermediate phase $\mathrm{AlPO}_{4}-54 \bullet 1 / 2 \mathrm{H}_{2} \mathrm{O}$ corresponding to a form with empty pores, but with some remaining structural $\mathrm{H}_{2} \mathrm{O}$ in the Al-centered polyhedra. At ambient temperature, the vacuum pressure appears to be a key parameter in the dehydration process. Adsorbed pore water is removed readily under primary vacuum followed by gradual removal of the structural water as a function of vacuum pressure. This information is particularly important in order to have a relatively straightforward method to activate $\mathrm{AlPO}_{4}-54$ without the need for heating in order to insert other guest species in the pores. Full dehydration of a single crystal was obtained using a primary vacuum without heating in contrast to previous studies and its crystal structure was refined in a monoclinic $\mathrm{Cm}$ space group with a doubled $c$ cell parameter.

\section{Acknowledgments}


We acknowledge the PRIN project ZAPPING, number 2015HK93L7, granted by the Italian Ministry of Education, Universities and Research, MIUR. The synchrotron single crystal X-ray diffraction experiments were performed at the Xpress beamline from Elettra Sincrotrone Trieste (proposal number: 20195123). 


\section{REFERENCES}

[1] W.M. Meier, D.H. Olson, C. Baerlocher, Zeolites, 17 (1996) 1-229.

[2] M.E. Davis, C. Saldarriaga, C. Montes, J. Garces, C. Crowder, Zeolites, 8 (1988) 362-366.

[3] L.B. McCusker, C. Baerlocher, E. Jahn, M. Bulow, Zeolites, 11 (1991) 308-313.

[4] F.G. Alabarse, J. Haines, O. Cambon, C. Levelut, D. Bourgogne, A. Haidoux, D. Granier, B. Coasne, Phys. Rev. Lett., 109 (2012).

[5] F.G. Alabarse, J. Rouquette, B. Coasne, A. Haidoux, C. Paulmann, O. Cambon, J. Haines, J. Am. Chem. Soc., 137 (2015) 584-587.

[6] G. Cheetham, M.M. Harding, Zeolites, 16 (1996) 245-248

[7] J.W. Richardson, J.V. Smith, J.J. Pluth, J. Phys. Chem., 93 (1989) 8212-8219.

[8] D.M. Poojary, J.O. Perez, A. Clearfield, J. Phys. Chem., 96 (1992) 7709-7714.

[9] J. De Oñate Martinez, L.B. McCusker, C. Baerlocher, Micropor. Mesopor. Mat., 34 (2000) 99-113.

[10] M.J. Annen, D. Young, M.E. Davis, O.B. Cavin, C.R. Hubbard, J. Phys. Chem., 95 (1991) 13801383.

[11] J.A. Martens, E. Feijen, J.L. Lievens, P.J. Grobet, P.A. Jacobs, J. Phys. Chem., 95 (1991) 1002510031.

[12] W. Schmidt, F. Schuth, H. Reichert, K. Unger, B. Zibrowius, Zeolites, 12 (1992) 2-8.

[13] E.T.C. Vogt, J.W. Richardson, J. Solid State Chem., 87 (1990) 469-471.

[14] M. Stöcker, D. Akporiaye, K.-P. Lillerud, Appl. Catalysis, 69 (1991) L7-L13.

[15] F.G. Alabarse, J.-B. Brubach, P. Roy, A. Haidoux, C. Levelut, J.-L. Bantignies, O. Cambon, J. Haines, J. Phys. Chem. C, 119 (2015) 7771-7779.

[16] J. De Oñate Martinez, C. Falamaki, C. Baerlocher, L.B. McCusker, Micropor. Mesopor. Mat., 28 (1999) 261-269.

[17] F.G. Alabarse, G. Silly, A. Haidoux, C. Levelut, D. Bourgogne, A.M. Flank, P. Lagarde, A.S. Pereira, J.L. Bantignies, O. Cambon, J. Haines, J. Phys. Chem. C, 118 (2014) 3651-3663.

[18] M. Santoro, A. Hajeb, F.A. Gorelli, High Pressure Res., (2020), doi.org/10.1080/08957959.2020.1789619.

[19] A.P. Hammersley, S.O. Svensson, M. Hanfland, A.N. Fitch, D. Hausermann, High Pressure Res., 14 (1996) 235-248.

[20] P. Lotti, S. Milani, M. Merlini, B. Joseph, F. Alabarse, A. Lausi, J. Synchrotron Radiat., 27 (2020) 222-229.

[21] G.M. Sheldrick, Acta Crystallogr. Sect. A, 69 (2013) S74-S74.

[22] K. Momma, F. Izumi, J. Appl. Crystallogr., 44 (2011) 1272-1276.

[23] J. Rodriguez-Carvajal, Applied Crystallography, (2001) 30-36.

[24] N.A. Sennova, R.S. Bubnova, S.K. Filatov, P. Paufler, D.C. Meyer, A.A. Levin, I.G. Polyakova, Cryst. Res. Technol., 40 (2005) 563-572

[25] H.Y. He, W. Kolodziejski, J. Klinowski, Chem. Phys. Lett., 200 (1992) 83-87.

[26] Y. Wu, B.F. Chmelka, A. Pines, M.E. Davis, P.J. Grobet, P.A. Jacobs, Nature, 346 (1990) 550-552. 
Table 1. Cell parameters for $\mathrm{AlPO}_{4}-54 \cdot x \mathrm{H}_{2} \mathrm{O}$ (hexagonal, $P 6_{3}$ ) and $\mathrm{AlPO}_{4}-54$ (monoclinic $C m, \beta=90^{\circ}$ ). Data for the majority phase are given for two-phase mixtures.

\begin{tabular}{|c|c|c|c|c|}
\hline Sample & $a(\AA)$ & $b(\AA)$ & $c(\AA)$ & $\begin{array}{l}c / a \quad \text { (hexagonal } \\
\text { subcell) }\end{array}$ \\
\hline Powder & $18.9878(3)$ & $18.9878(3)$ & $8.1198(2)$ & $0.42763(2)$ \\
\hline $\begin{array}{l}\text { Powder } 8.9 \mathrm{~Pa}(1.5 \mathrm{~h}) \\
\text { partially dehydrated majority phase }\end{array}$ & $18.553(1)$ & $32.151(1)$ & $16.712(1)$ & $0.45038(4)$ \\
\hline $\begin{array}{l}\text { Powder } 0.011 \mathrm{~Pa}(22.75 \mathrm{~h}) \\
\text { anhydrous majority phase }\end{array}$ & $18.567(1)$ & $32.131(1)$ & $16.816(1)$ & $0.45262(4)$ \\
\hline Recovered Powder & $18.9897(3)$ & $18.9897(3)$ & $8.1234(2)$ & $0.42777(2)$ \\
\hline Single crystal & $18.9606(7)$ & $18.9606(7)$ & $8.0945(2)$ & $0.42691(6)$ \\
\hline Single crystal $4 \mathrm{~Pa}(15 \mathrm{~min})$ & $18.933(2)$ & $18.933(2)$ & $8.0954(9)$ & $0.42758(9)$ \\
\hline Single crystal $2.7 \mathrm{~Pa}(16 \mathrm{~h})$ & $18.473(10)$ & $32.031(7)$ & $16.747(3)$ & $0.4533(3)$ \\
\hline
\end{tabular}




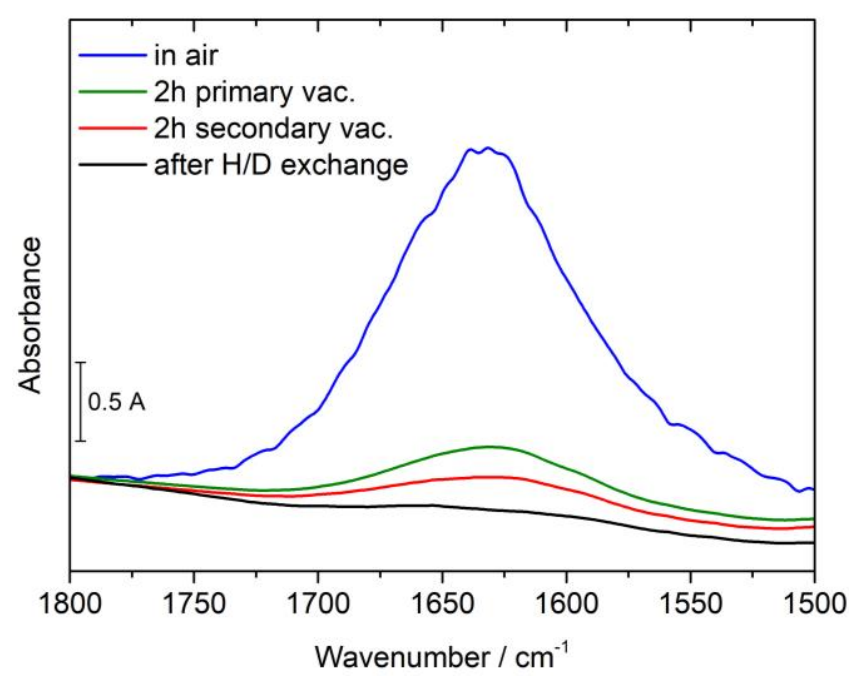

Figure 1. Infrared spectra of $\mathrm{AlPO}_{4}-54$ as a function of vacuum pressure and time.

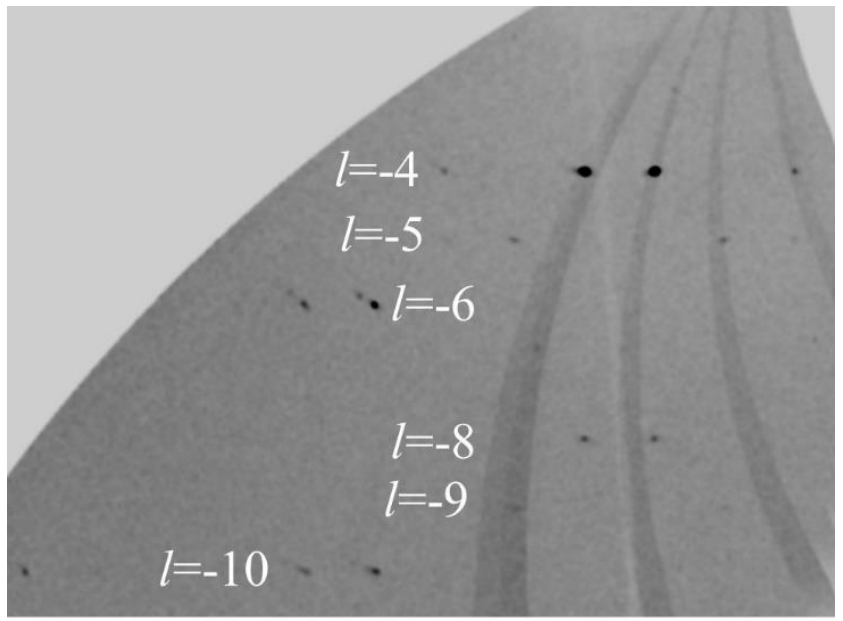

Figure 2. Selected zone of the $1 \mathrm{kl}$ reciprocal lattice reconstruction for the single crystal of dehydrated $\mathrm{AlPO}_{4}-54$. The successive observed horizontal $1 \mathrm{kl}(\mathrm{l}=-4,-5,-6,-8,-9,-10)$ layers are labelled. Odd values of $l$ correspond to superlattice reflections for the original hexagonal cell. 

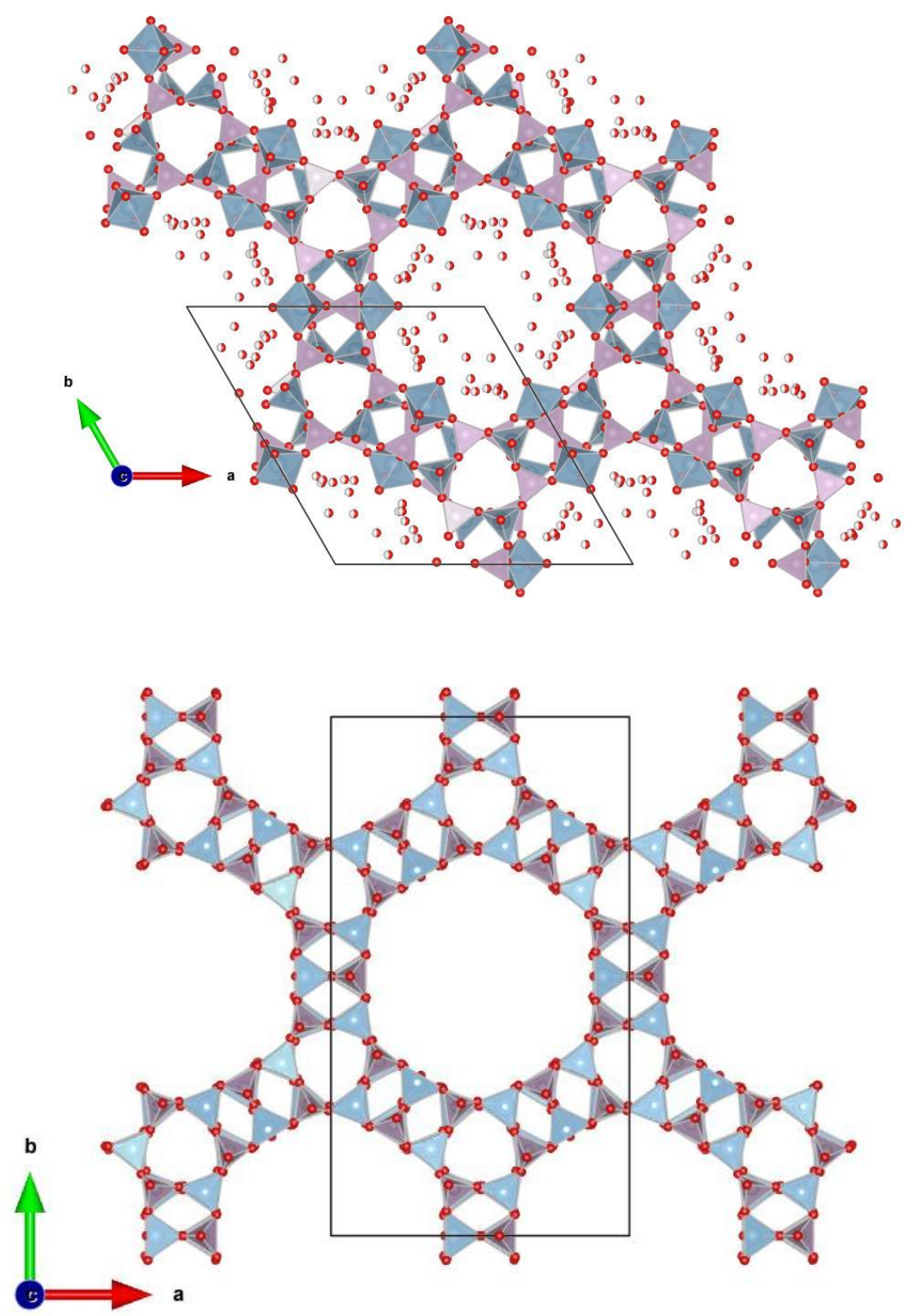

Figure 3. Crystal structures of hydrated (top) and anhydrous (bottom) $\mathrm{AlPO}_{4}-54$. 


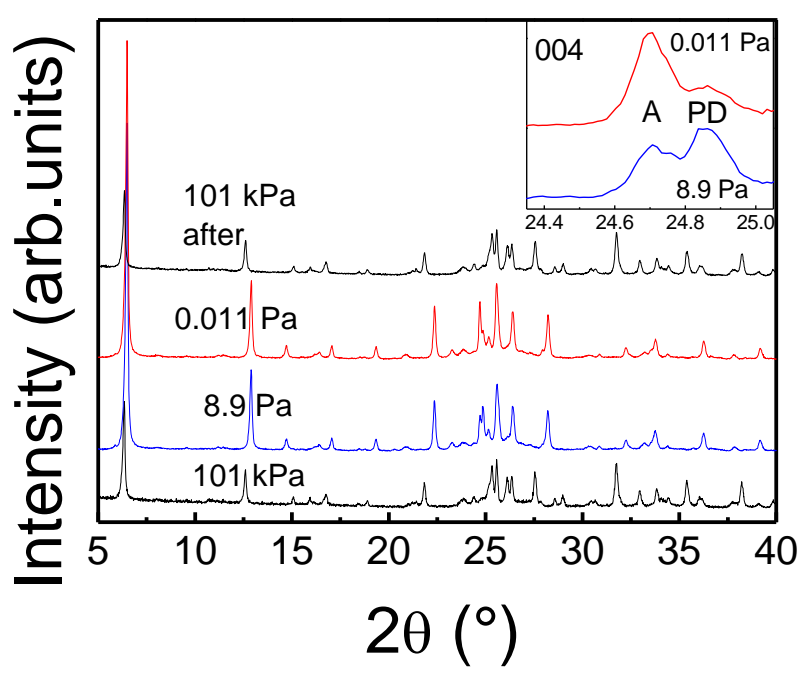

Figure 4. X-ray diffraction patterns of $\mathrm{AlPO}_{4}-54$ as a function of vacuum pressure and after release of the vacuum. Inset: region of the 004 reflection from the partially dehydrated (PD) and anhydrous (A) forms of $\mathrm{AlPO}_{4}-54$.

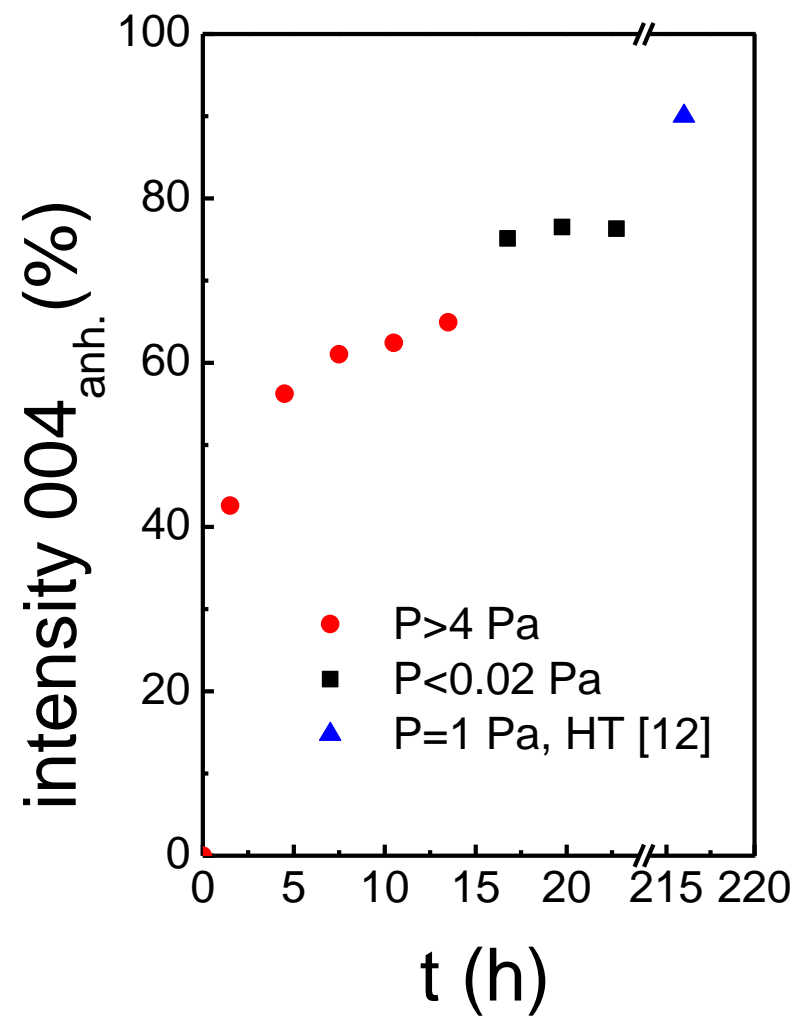

Figure 5. Relative intensity of the 004 reflection of the anhydrous $\mathrm{AlPO}_{4}-54$ phase with respect to the sum of the intensities of the 004 reflections from partially and fully dehydrated $\mathrm{AlPO}_{4}-54$ as a function of time under vacuum. 


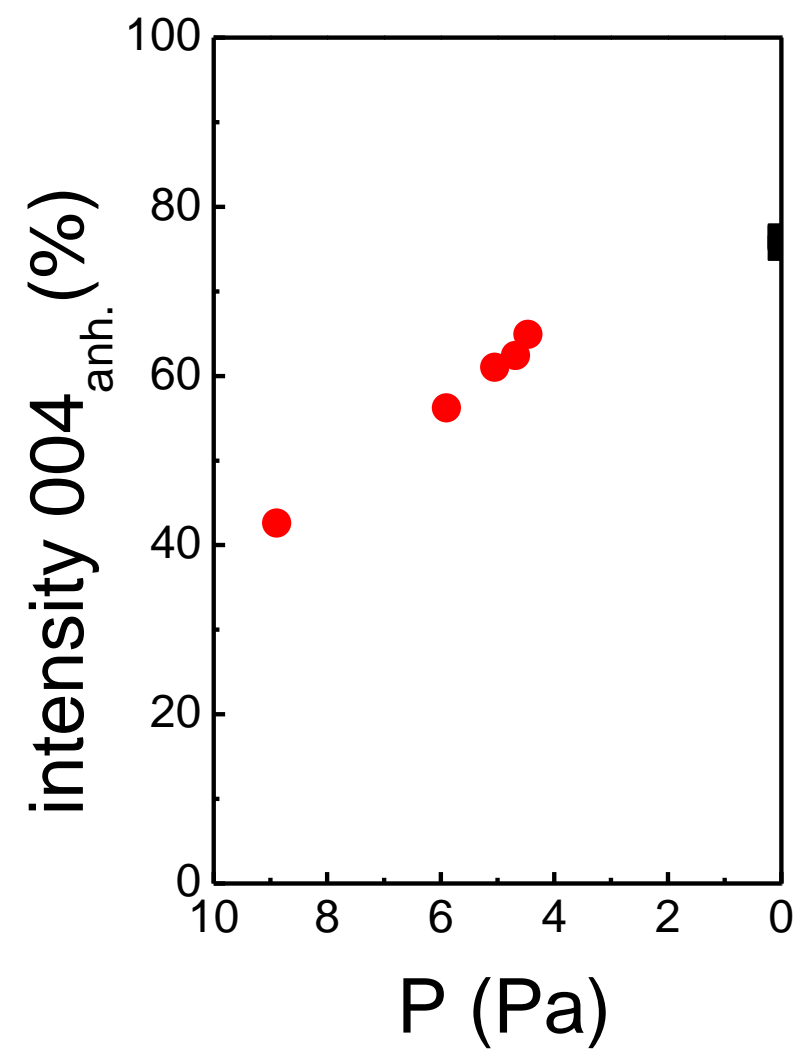

Figure 6. Relative intensity of the 004 reflection of the anhydrous $\mathrm{AlPO}_{4}-54$ phase with respect to the sum of the intensities of the 004 reflections from partially and fully dehydrated $\mathrm{AlPO}_{4}-54$ as a function of vacuum pressure. 